\title{
Cetuximab inhibits cisplatin-induced activation of EGFR signaling in esophageal squamous cell carcinoma
}

\author{
JUNHYE KWON ${ }^{1,2}$, HYEON-JOON YOON ${ }^{1}$, JI-HEE KIM ${ }^{1}$, TAE SUP LEE ${ }^{3}$, IN HO SONG ${ }^{3}$, \\ HAE WON LEE ${ }^{4}$, MOON CHUL KANG ${ }^{4}$ and JONG HO PARK ${ }^{4}$
}

\author{
${ }^{1}$ Department of Translational Research, Korea Cancer Center Hospital, Korea Institute of Radiological and \\ Medical Sciences, Seoul; ${ }^{2}$ Research Institute of Women's Health, Sookmyung Women's University, Seoul; \\ ${ }^{3}$ Molecular Imaging Research Center and ${ }^{4}$ Department of Thoracic Surgery, Korea Cancer Center \\ Hospital, Korea Institute of Radiological and Medical Sciences, Seoul, Republic of Korea
}

Received March 20, 2014; Accepted June 13, 2014

DOI: 10.3892/or.2014.3302

\begin{abstract}
A malignant esophageal cancer, squamous cell carcinoma is one of the most prevalent cancers. Despite the use of present surgical techniques combined with various treatment modalities, the overall 5-year survival rate remains at $15-34 \%$. Epidermal growth factor receptor (EGFR) is the most well studied receptor in various cancers and EGFR overexpression is detected in $40 \%$ of esophageal squamous cell carcinomas (ESCCs) and ESCC cell lines. To examine the EGFR antibody combination effect, we used treatment with cisplatin and cetuximab in ESCC cell lines, TE-4 and TE-8. Combination of cetuximab and cisplatin resulted in a growth inhibition only in the EGFR overexpressed TE-8 cell line. Furthermore, we confirmed that cisplatin-induced EGFR activation was inhibited by cetuximab in TE- 8 but not in TE- 4 cells. Our data suggest that cetuximab combined with cisplatin exerts antitumorigenic effects in vitro and in vivo via suppression of EGF signaling, which can be applied toward targeted ESCC treatments.
\end{abstract}

\section{Introduction}

Esophageal squamous cell carcinoma (ESCC) is an aggressive disease characterized by high mortality rates. Epidemiological studies indicate that ESCC is the fifth most common cause of cancer-related mortality in men (1). Despite significant improvements in diagnosis and treatment including surgery, chemotherapy and radiotherapy, patient prognosis remains poor, with a 5-year survival rate of $15-34 \%$ (2-4). Systemic chemotherapy with cisplatin and 5-fluorouracil (5-FU) is the most commonly used treatment regimen for advanced ESCC. However, response rates are low at 15-45\% and median survival

Correspondence to: Dr Jong Ho Park, Department of Thoracic Surgery, Korea Cancer Center Hospital, Korea Institute of Radiological and Medical Sciences, Seoul 139-706, Republic of Korea

E-mail: jhpark@kcch.re.kr

Key words: esophageal squamous cell carcinoma, epidermal growth factor receptor, cisplatin, cetuximab is generally $<8$ months $(5,6)$. Therefore, novel therapeutic agents are urgently needed to improve clinical outcomes.

Epidermal growth factor receptor (EGFR) is the most extensively studied of the ErbB receptors in relation to cancer. EGFR is overexpressed in 60-70\% of ESCC cases and EGFR gene amplification was detected in approximately $28 \%$ of tumors by fluorescence in situ hybridization (7). Activated EGFR signals via the AKT, ERK and RAS pathways and has an essential role in the control of many fundamental cellular processes. As such, the inhibition of EGFR signaling has emerged as an important antitumor treatment strategy. Cetuximab (also known as Erbitux or C225) is a recombinant chimeric human-murine monoclonal antibody and is among the most promising and clinically effective of these agents (8-10). Cetuximab binds EGFR with high affinity and prevents receptor activation, thereby suppressing proliferation and angiogenesis and promoting antibody-dependent cellular toxicity (11). When administered in conjunction with the platinum-based chemotherapy drug cisplatin, treatment with cetuximab resulted in a longer overall survival time in patients with recurrent or metastatic head and neck SCC (HNSCC) (12). However, despite several clinical trials for cetuximab and cisplatin, the precise role of these agents in the regulation of the EGFR signaling pathway is unclear.

The present study investigated the molecular mechanisms of cetuximab and cisplatin in two ESCC cell lines in the regulation of EGF signaling and assessed the potential for combination therapy in vitro and in vivo.

\section{Materials and methods}

Reagents and antibodies. The humanized mouse anti-human EGFR antibody cetuximab was purchased from Merck (Dietikon, Switzerland) and cisplatin was obtained from Dong-A PharmTech Co., Ltd. (Seoul, Korea). Primary antibodies against EGFR, phosphorylated p-EGFR, AKT, p-AKT, ERK and p-ERK were purchased from Santa Cruz Biotechnology (Santa Cruz, CA, USA) and Cell Signaling Technology (Boston, MA, USA). Horseradish peroxidase (HRP)-conjugated secondary antibody was from Santa Cruz Biotechnology. 
Cell culture. Human ESCC cell lines TE-1, -2, -4, -5, -6, -8, $-9,-10,-11,-14$ and -15 were obtained from RIKEN (Tsukuba, Japan) and the human primary esophageal epithelial cell line Het-1A was purchased from American Type Culture Collection (Manassas, VA, USA). Cells were cultured in RPMI-1640 medium supplemented with $10 \%(\mathrm{v} / \mathrm{v})$ fetal bovine serum (FBS) and antibiotics $(100 \mathrm{U} / \mathrm{ml}$ penicillin and $100 \mu \mathrm{g} / \mathrm{ml}$ streptomycin) at $37^{\circ} \mathrm{C}$ under $5 \% \mathrm{CO}_{2}$ and $95 \%$ air.

Cell viability assay. Cells were seeded at $4 \times 10^{3} /$ well in 96-well plates in $0.1 \mathrm{ml}$ medium for $24 \mathrm{~h}$ before treatment. Cells were exposed to a range of concentrations of cetuximab, cisplatin, or both in the presence of $0.5 \%$ FBS. At the indicated time points, CellTiter 96 AQueous (MTS) solution (Promega, Madison, WI, USA) in serum-free medium was added to each well. After $2 \mathrm{~h}$, the colored MTS product in the supernatant was measured using a microplate reader (BioTek, Winooski, USA) at $490 \mathrm{~nm}$ absorbance.

Western blot analysis. Protein was extracted from cells and frozen tissues using RIPA buffer (Thermo Fisher Scientific, Waltham, MA, USA) containing protease inhibitors (Roche, Basel, Switzerland). Lysates containing equivalent amounts of protein were resolved by $10 \%$ SDS-PAGE. Samples were transferred to nitrocellulose membranes, which were blocked in 5\% skim milk in TBS containing $0.1 \%$ Tween-20. Membranes were probed overnight at $4^{\circ} \mathrm{C}$ with primary antibodies against EGFR $(1: 3,000)$, p-EGFR $(1: 1,000)$, AKT, p-AKT (both 1:1,000), ERK $(1: 1,000)$ and p-ERK $(1: 1,000)$; the following day, HRP-conjugated secondary antibody $(1: 5,000)$ was applied for $1 \mathrm{~h}$ at room temperature. Protein was visualized using the enhanced chemiluminescence detection system (Thermo Fisher Scientific).

Immunohistochemistry. Formalin-fixed, paraffin-embedded tumor tissue samples were sectioned at a thickness of $4 \mu \mathrm{m}$ and mounted on glass slides. Endogenous peroxidase was blocked by treating sections with $0.3 \% \mathrm{H}_{2} \mathrm{O}_{2}$ for $30 \mathrm{~min}$. Antigen retrieval was performed in a steamer with citrate buffer for 30 min. Immunostaining was performed using a Lab Vision Autostainer (Thermo Scientific, Bremen, Germany) and primary antibodies against EGFR (1:500) and Ki67 (1:300), followed by treatment with the Lab Vision HRP polymer detection system (Thermo Scientific) according to the manufacturer's protocol. The TUNEL reaction was performed according to the manufacturer's instructions. Stained sections were visualized using a light microscope (Olympus, Tokyo, Japan).

Subcutaneous xenograft model. Animals were housed and treated in accordance with institutional guidelines for animal care and use. Female athymic mice (BALB/c-nu/nu; 5-6 weeks old; $17-23 \mathrm{~g}$ ) were injected subcutaneously with TE-8 cells $\left(1.5 \times 10^{7}\right)$ in the right flank. Tumors were allowed to grow to a volume of approximately $100 \mathrm{~mm}^{3}$, at which time mice were randomly assigned to one of four groups (10 animals each). One group received intraperitoneal (i.p.) injections of cisplatin at doses of $40 \mu \mathrm{g} /$ head per injection three times a week. A second group was administered cetuximab intravenously at $0.5 \mathrm{mg} / \mathrm{head}$ per week. In the third group, both cisplatin and cetuximab were administered using the same schedule



Figure 1. Relative levels of EGFR, p-EGFR, AKT, p-AKT, ERK and p-ERK expression in ESCC cell lines (TE-1, -2, -4, -5, -6, -8, -9, -10, -11, -14 and -15) and a normal esophageal epithelial cell line (Het-1A), as determined by western blot analysis. $\beta$-actin was used as a loading control.

for each drug as for single treatments. The fourth group, the control group, received i.p. injections of saline. The tumor volume and weight of each animal were assessed every other day for 4 weeks. Tumor volumes (V) were estimated using the formula: $\mathrm{V}=$ length $\mathrm{x}$ width ${ }^{2} / 2$.

Statistical analysis. Data were obtained from at least three independent experiments and are expressed as mean \pm standard deviation. Mean differences were analyzed using the Student's t-test. A P-value $<0.05$ was considered to indicate a statistically significant difference.

\section{Results}

Expression and phosphorylation status of EGFR, AKT and ERK in ESCC cell lines. The expression of EGFR, p-EGFR, AKT, p-AKT, ERK, p-ERK was examined in 10 ESCC and control Het-1A cell lines by western blotting (Fig. 1). TE-8 and -11 cells showed the highest expression of EGFR and p-EGFR, whereas activated EGFR (i.e., p-EGFR) levels were low in the other cell lines, including TE-4. Levels of p-AKT and p-ERK did not differ significantly between cell lines. Two cell lines, TE-4 and -8, were selected for subsequent experiments to examine the correlation between EGFR and p-EGFR expression and combined drug treatment.

Cisplatin-induced cytotoxicity is enhanced by cetuximab in EGFR-activated cells. The effects of cisplatin and cetuximab administered in isolation or in combination were assessed in two ESCC cell lines, TE-4 and -8, expressing low and high endogenous levels of EGFR, respectively. A range of concentrations of both agents were tested (cisplatin: 0, 1, 2, 5, 10 and $20 \mu \mathrm{M}$ for 3 days; cetuximab: $0,10,50,100,200$ and $400 \mu \mathrm{g} / \mathrm{ml}$ for 7 days). TE-8 had greater sensitivity to cisplatin than TE-4 cells, with $\mathrm{IC}_{50}$ values of 2.06 and 16.79, respectively (Fig. 2A). There was no difference in sensitivity to cetuximab between the two cell lines $\left(\mathrm{IC}_{50}=232.65\right.$ in TE- 4 vs. 230.35 in TE-8) (Fig. 2B). Cell viability was examined in cells treated with either or both agents. A dose-dependent, overall decrease in cell viability was observed; combined treatment with cisplatin 

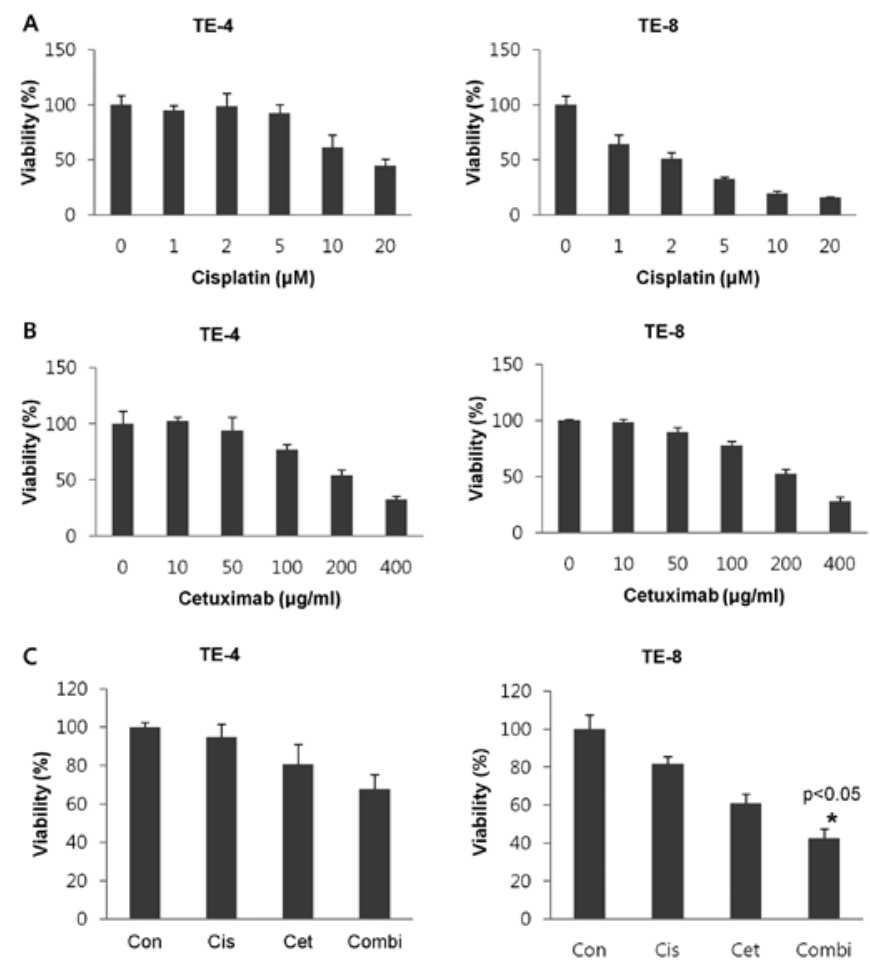

Figure 2. Effects of cisplatin, cetuximab and a combination of both on ESCC cell growth, as determined by a colorimetric cell viability assay. TE-4 and -8 cells were treated with the indicated concentrations of (A) cisplatin, (B) cetuximab, or (C) $1 \mu \mathrm{M}$ cisplatin and $400 \mu \mathrm{g} / \mathrm{ml}$ cetuximab.

and cetuximab had an additive cytotoxic effect compared to single treatments $(\mathrm{P}<0.05)$ in the EGFR-overexpressing TE-8 but not in TE-4 cells (Fig. 2C).

Activation of EGF signaling by cisplatin in EGFR-expressing cells. To determine the mechanism underlying cisplatin- and cetuximab-induced inhibition of ESCC cell growth, the expression and phosphorylation status of EGFR and AKT were examined in TE- 4 and -8 cells by western blotting. Expression of EGFR, p-EGFR and p-AKT was upregulated by cisplatin treatment in a dose-dependent manner in TE- 8 but not TE-4 cells (Fig. 3A), indicating an activation of EGF signaling. In contrast, treatment of TE- 8 cells with cetuximab led to a dose-dependent decrease in EGFR, p-EGFR and p-AKT expression (Fig. 3B). The cisplatin-induced increases in EGFR, $\mathrm{p}$-EGFR and p-AKT expression in TE-8 cells were abrogated in the presence of cetuximab (Fig. 2C). In TE-4 cells, cisplatin had no effect on EGFR, p-EGFR and p-AKT levels; treatment with cetuximab, or a combination of both agents, led to a decrease in p-AKT expression but had no effect on the expression or phosphorylation of EGFR.

Antitumorigenic effects of cisplatin combined with cetuximab in an ESCC xenograft model. The effects of cisplatin and cetuximab on tumor growth were investigated in an ESCC mouse model. The volume of TE- 8 cell-derived tumors was reduced by 13.5 and $39.1 \%$ upon treatment with cisplatin and cetuximab, respectively, compared to saline-treated controls (Fig. 4A), demonstrating that cetuximab has an anti-tumorigenic effect in vivo. Combined treatment with cisplatin and

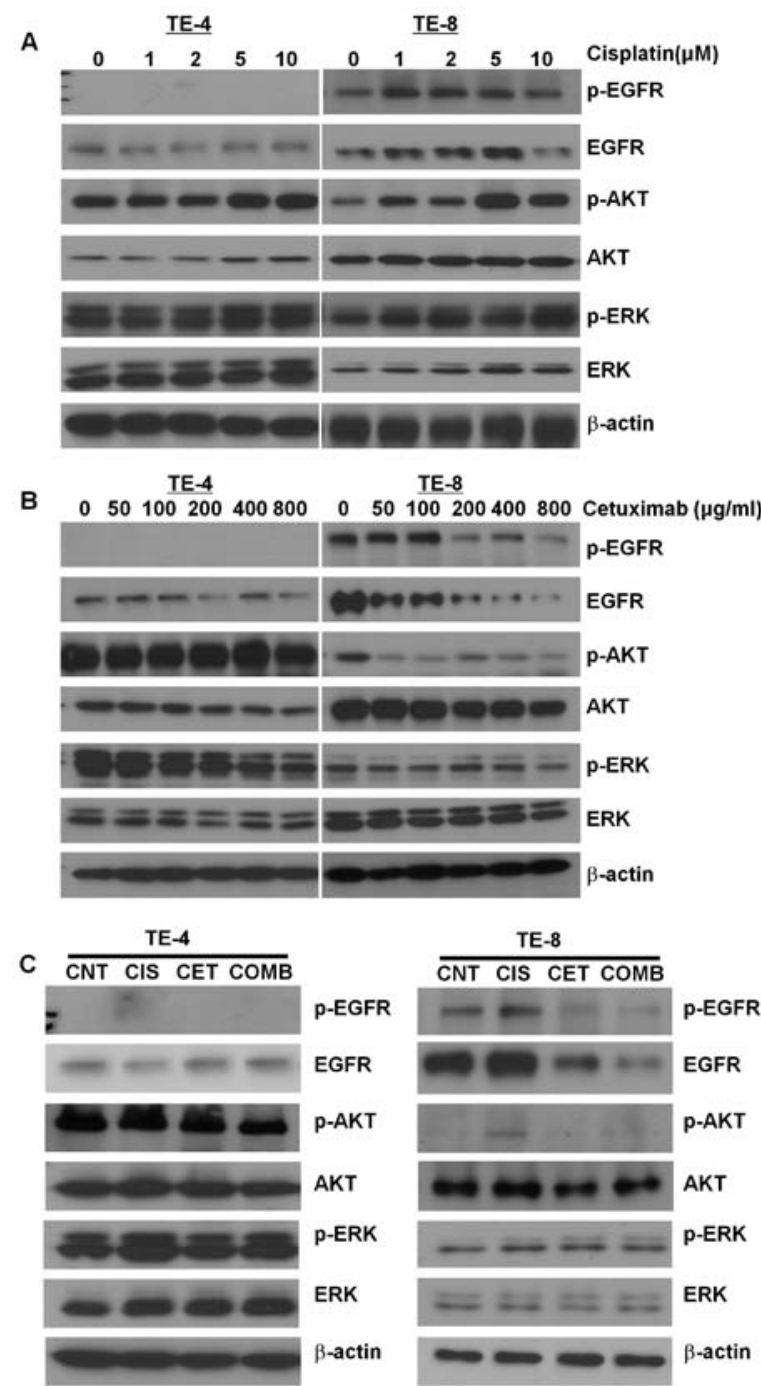

Figure 3. Modulation of cisplatin-induced EGFR activation by cetuximab in ESCC cells, as determined by western blotting. (A) EGFR and AKT were activated in a dose-dependent manner by cisplatin in TE- 8 but not TE- 4 cells, as assessed by increased expression of p-EGFR and p-AKT, respectively (B) Activation of EGFR and AKT was suppressed in a dose-dependent manner by cetuximab in TE-8 cells. (C) Cisplatin-induced expression and activation of EGFR and AKT was inhibited by cetuximab in TE- 8 but not TE- 4 cells.

cetuximab decreased tumor volume by $63.2 \%$, suggesting that the treatment of cetuximab and cisplatin as a combination therapy may be promising in a TE-8 cell-derived ESCC tumor model.

EGFR expression and phosphorylation were examined in tumor tissue samples by western blotting (Fig. 4B). Consistent with in vitro observations, EGFR and p-EGFR levels were higher in tumors from the cisplatin treatment group, while levels were downregulated in the combination treatment group, effects that were confirmed by immunohistochemistry (Fig. 4C). EGFR expression was reduced in necrotic areas of cetuximab- or combination-treated tumor tissue samples. Moreover, the Ki67-expressing proliferative fraction was decreased after treatment with cisplatin (by $29 \%$ vs. control; $\mathrm{P}<0.001$ ), cetuximab (by $38 \%$ vs. control; $\mathrm{P}<0.001$ ), or both (by $66 \%$ vs. control; $\mathrm{P}<0.001$ ). No differences in the fraction of apoptotic cells were observed between the various treatment groups. 



B

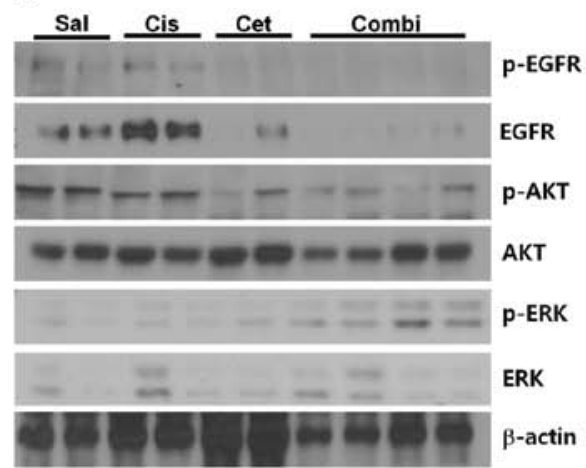

C

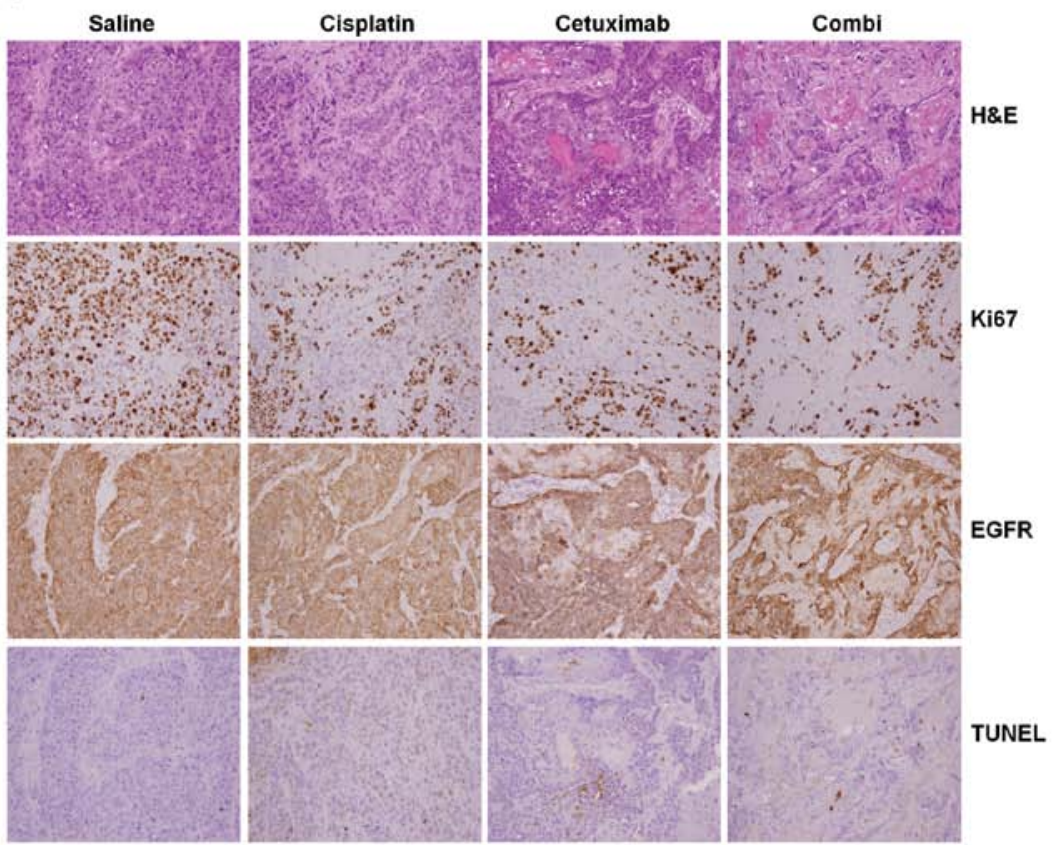

Figure 4. Effect of cisplatin, cetuximab and a combination treatment on tumor growth in vivo. Immunocompromised mice with TE-8 cell-derived xenografts $\left(100 \mathrm{~mm}^{3}\right)$ were treated with cisplatin $(40 \mu \mathrm{g} / \mathrm{head})$, cetuximab $(0.5 \mathrm{mg} / \mathrm{head})$, or both, while control animals were injected with saline. (A) Average tumor volume was assessed every other day for 4 weeks in the four treatment groups. (B) EGFR expression and activation were assessed in tumor tissue samples by western blotting. Tumors in the combined cisplatin/cetuximab treatment group expressed decreased levels of EGFR and p-EGFR. (C) A decrease in EGFR expression in tumors derived from cetuximab and combination treatment groups was observed by immunohistochemistry. Low levels of tumor cell proliferation were detected by Ki67 immunostaining in cisplatin, cetuximab and combination treatment groups.

\section{Discussion}

Esophageal cancer is one of the leading causes of cancer mortality worldwide and is the fifth most common cause of cancer-related mortality in men (1). Approximately half of patients diagnosed with esophageal cancer present with overt metastatic disease and chemotherapy is the treatment of choice for advanced stages. ESCC patients often receive a combination of drugs such as cisplatin, 5-FU, etoposide and paclitaxel (13). Despite the widespread use of combination chemotherapy, there is no solid evidence for significant improvements in overall survival rate using this strategy. Previous studies have examined the effects of treatment using a combination of an anti-EGFR antibody (e.g., cetuximab) and a conventional drug (e.g., cisplatin) on cell lines derived from colon cancer, non-small cell lung cancer and cervical cancer $(14,15)$. However, little is known about the effects of this combination of agents in ESCC cells.

Results from recent clinical trials using a combination of cetuximab, cisplatin, irinotecan and radiotherapy to treat ESCC patients revealed significant adverse side-effects, such as diarrhea and dehydration, which were indicators of increased toxicity, without parallel increases in treatment efficacy $(16,17)$. Similarly, SCOPE1 trials in patients in the UK did not show any benefits to adding cetuximab to a standard chemo-/radiotherapy treatment regimen. However, in a multi- 
center phase II trial in Chinese patients with non-resectable, locally advanced ESCC, it was found that cetuximab can be safely used concurrently with chemo- and radiotherapy and may actually increase the clinical response rate $(18,19)$. The reasons for these conflicting results of cetuximab combination therapy remain unclear, but recent data point to the influence of mutations in, or amplification of, specific genes; for instance, combination therapy had different survival outcomes for patients depending on the presence of EGFR or MET gene amplifications, or mutations in EGFR, KRAS, or PI3CA $(20,21)$. The results of the present study, showing that the combined treatment effects are predominantly observed in an ESCC cell line overexpressing EGFR, support the theory that the choice and efficacy of treatment methods depend on the specific genotype of each patient.

The results of this study also underscore the complexity of the effects produced by combined treatment with cetuximab and cisplatin. For instance, the cytotoxic effects of the two agents used in combination were additive in TE-8 cells (Fig. 2), suggesting that it is promising as a treatment strategy. However, cisplatin-induced increases in EGF signaling were reversed by cetuximab treatment (Fig. 3). Given the role of phosphorylated EGFR in stimulating proliferation of some cancer cell types, this antagonistic interaction could be advantageous in ESCC treatment. Further studies on the downstream effects of EGF signaling in ESCC cells and a closer examination of the genotypic differences between different ESCC cell lines that could explain the differential responses to combined drug treatment, are required for the development of personalized and effective treatment regimens that are tailored to individual patients.

\section{Acknowledgements}

This study was supported by grants from the Radiological Translational Research Program (RTR) of the Korea Institute of Radiological and Medical Sciences (50455-2013).

\section{References}

1. Jemal A, Bray F, Center MM, Ferlay J, Ward E and Forman D Global cancer statistics. CA Cancer J Clin 61: 69-90, 2011.

2. Darling G: The role of lymphadenectomy in esophageal cancer. J Surg Oncol 99: 189-193, 2009.

3. Kranzfelder M, Schuster T, Geinitz H, Friess H and Buchler P: Meta-analysis of neoadjuvant treatment modalities and definitive non-surgical therapy for oesophageal squamous cell cancer. Br J Surg 98: 768-783, 2011.

4. Chiu PW, Chan AC, Leung SF, Leong HT, Kwong KH, Li MK, Au-Yeung AC, Chung SC and Ng EK: Multicenter prospective randomized trial comparing standard esophagectomy with chemoradiotherapy for treatment of squamous esophageal cancer: early results from the Chinese University Research Group for Esophageal Cancer (CURE). J Gastrointest Surg 9: 794-802, 2005.

5. Bleiberg H, Conroy T, Paillot B, Lacave AJ, Blijham G, Jacob JH, Bedenne L, Namer M, De Besi P, Gay F, Collette L and Sahmoud T: Randomised phase II study of cisplatin and 5-fluorouracil (5-FU) versus cisplatin alone in advanced squamous cell oesophageal cancer. Eur J Cancer 33: 1216-1220, 1997.

6. Polee MB, Kok TC, Siersema PD, Tilanus HW, Splinter TA, Stoter G and Van der Gaast A: Phase II study of the combination cisplatin, etoposide, 5-fluorouracil and folinic acid in patients with advanced squamous cell carcinoma of the esophagus. Anticancer Drugs 12: 513-517, 2001.

7. Hanawa M, Suzuki S, Dobashi Y, Yamane T, Kono K, Enomoto N and Ooi A: EGFR protein overexpression and gene amplification in squamous cell carcinomas of the esophagus. Int J Cancer 118: 1173-1180, 2006
8. Mendelsohn J and Baselga J: The EGF receptor family as targets for cancer therapy. Oncogene 19: 6550-6565, 2000.

9. Vermorken JB, Trigo J, Hitt R, Koralewski P, Diaz-Rubio E, Rolland F, Knecht R, Amellal N, Schueler A and Baselga J: Open-label, uncontrolled, multicenter phase II study to evaluate the efficacy and toxicity of cetuximab as a single agent in patients with recurrent and/or metastatic squamous cell carcinoma of the head and neck who failed to respond to platinum-based therapy. J Clin Oncol 25: 2171-2177, 2007.

10. Sobrero AF, Maurel J, Fehrenbacher L, Scheithauer W, Abubakr YA, Lutz MP, Vega-Villegas ME, Eng C, Steinhauer EU, Prausova J, Lenz HJ, Borg C, Middleton G, Kroning H, Luppi G, Kisker O, Zubel A, Langer C, Kopit J and Burris HA III: EPIC: phase III trial of cetuximab plus irinotecan after fluoropyrimidine and oxaliplatin failure in patients with metastatic colorectal cancer. J Clin Oncol 26: 2311-2319, 2008.

11. Vincenzi B, Schiavon G, Silletta M, Santini D and Tonini G: The biological properties of cetuximab. Crit Rev Oncol Hematol 68: 93-106, 2008

12. Vermorken JB, Mesia R, Rivera F, Remenar E, Kawecki A, Rottey S, Erfan J, Zabolotnyy D, Kienzer HR, Cupissol D, Peyrade F, Benasso M, Vynnychenko I, De Raucourt D, Bokemeyer C, Schueler A, Amellal N and Hitt R: Platinum-based chemotherapy plus cetuximab in head and neck cancer. N Engl J Med 359: 1116-1127, 2008.

13. Ilson DH: Esophageal cancer chemotherapy: recent advances. Gastrointest Cancer Res 2: 85-92, 2008.

14. Cascone T, Morelli MP, Morgillo F, Kim WY, Rodolico G, Pepe S, Tortora G, Berrino L, Lee HY, Heymach JV and Ciardiello F: Synergistic anti-proliferative and pro-apoptotic activity of combined therapy with bortezomib, a proteasome inhibitor, with anti-epidermal growth factor receptor (EGFR) drugs in human cancer cells. J Cell Physiol 216: 698-707, 2008.

15. Meira DD, de Almeida VH, Mororo JS, Nobrega I, Bardella L, Silva RL, Albano RM and Ferreira CG: Combination of cetuximab with chemoradiation, trastuzumab or MAPK inhibitors: mechanisms of sensitisation of cervical cancer cells. Br J Cancer 101: 782-791, 2009.

16. Tomblyn MB, Goldman BH, Thomas CR,Jr, Benedetti JK, Lenz HJ, Mehta V, Beeker T, Gold PJ, Abbruzzese JL, Blanke CD and SWOG GI Committee: Cetuximab plus cisplatin, irinotecan, and thoracic radiotherapy as definitive treatment for locally advanced, unresectable esophageal cancer: a phase-II study of the SWOG (S0414). J Thorac Oncol 7: 906-912, 2012.

17. Lee MS, Mamon HJ, Hong TS, Choi NC, Fidias PM, Kwak EL, Meyerhardt JA, Ryan DP, Bueno R, Donahue DM, Jaklitsch MT, Lanuti M, Rattner DW, Fuchs CS and Enzinger PC: Preoperative cetuximab, irinotecan, cisplatin, and radiation therapy for patients with locally advanced esophageal cancer. Oncologist 18 : 281-287, 2013.

18. Meng X, Wang J, Sun X, Wang L, Ye M, Feng P, Zhu G, Lu Y, Han C, Zhu S, Liao Z and Yu J: Cetuximab in combination with chemoradiotherapy in Chinese patients with non-resectable, locally advanced esophageal squamous cell carcinoma: a prospective, multicenter phase II trail. Radiother Oncol 109: 275-280, 2013.

19. Crosby T, Hurt CN, Falk S, Gollins S, Mukherjee S, Staffurth J, Ray R, Bashir N, Bridgewater JA, Geh JI, Cunningham D, Blazeby J, Roy R, Maughan T and Griffiths G: Chemoradiotherapy with or without cetuximab in patients with oesophageal cancer (SCOPE1): a multicentre, phase $2 / 3$ randomised trial. Lancet Oncol 14: 627-637, 2013.

20. Lennerz JK, Kwak EL, Ackerman A, Michael M, Fox SB, Bergethon K, Lauwers GY, Christensen JG, Wilner KD, Haber DA, Salgia R, Bang YJ, Clark JW, Solomon BJ and Iafrate AJ: MET amplification identifies a small and aggressive subgroup of esophagogastric adenocarcinoma with evidence of responsiveness to crizotinib. J Clin Oncol 29: 4803-4810, 2011.

21. Kwak EL, Jankowski J, Thayer SP, Lauwers GY, Brannigan BW, Harris PL, Okimoto RA, Haserlat SM, Driscoll DR, Ferry D, Muir B, Settleman J, Fuchs CS, Kulke MH, Ryan DP, Clark JW, Sgroi DC, Haber DA and Bell DW: Epidermal growth factor receptor kinase domain mutations in esophageal and pancreatic adenocarcinomas. Clin Cancer Res 12: 4283-4287, 2006. 